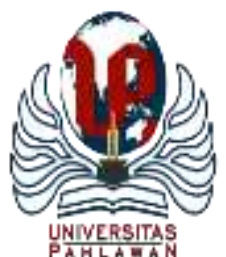

\title{
JURNALBASICEDU
}

Volume 5 Nomor 6 Tahun 2021 Halaman 5241 - 5248

Research \&Learningin Elementary Education https://jbasic.org/index.php/basicedu

\section{Membina Karakter Bangsa Indonesia untuk Anak Sekolah Dasar melalui Pendidikan Kewarganegaraan}

\section{Dinie Anggraeni Dewi ${ }^{1}$, Solihin Ichas Hamid ${ }^{2}$, Maharani Sartika Dewi ${ }^{3 凶}$, Patricia Bunga Juwita Galand ${ }^{4}$, Wenny Yolandha ${ }^{5}$}

Pendidikan Guru Sekolah Dasar, Universitas Pendidikan Indonesia, Indonesia ${ }^{2,3,4,5}$

E-mail: dinieanggraenidewi@ upi.edu ${ }^{1}, \underline{\text { solihinichas @ upi.edu }}{ }^{2}, \underline{\text { maharanisartika@upi.edu }}^{3}$, patriciabunga@upi.edu ${ }^{4}, \underline{\text { wenny08@upi.edu }}{ }^{5}$

\begin{abstract}
Abstrak
Pembangunan karakter bagi anak usia sekolah dasar merupakan hal yang sangat penting. Dalam lingkup sekolah, pembentukan karakter dan moralitas bangsa ini diajarkan melalui mata pelajaran pendidikan kewarganegaraan. Tujuan dari penelitian ini adalah mengkaji pendidikan kewarganegaraan dalam implementasi karakter dan moralitas anak usia sekolah dasar. Penelitian ini menggunakan penelitian kualitatif studi pustaka dengan memanfaatkan buku-bukudan literatur-literatur lainnya dengan menjadikannya sebagai objek yang dalam penelitiannya sendiri dapat menghasilkan informasi yang berupa catatan dan data deskriptif yang ada pada teks yang akan diteliti dalampenelitian ini. Hasil penelitian ini menunjukan bahwa pemberian mata pelajaran pendidikan kewarganegaraan dapat digunakan sebagai pembangun karakter bangsa Indonesia bagi anak sekolah dasar.
\end{abstract}

Kata Kunci: Pendidikan Kewarganegaraan, Pembangunan Karakter, Karakter Bangsa

\begin{abstract}
Character building for elementary school age children is very important. Within the scope of schools, the formation of the character and morality of this nation is taught through civic education subjects. The purpose of this study is to examine civic education in the implementation of character and morality for elementary school-aged children. This study uses a qualitative research literature study by utilizing books and other literature by making it an object which in its own research can produce information in the form of notes and descriptive data contained in the text to be studied in this study. The results of this study indicate that the provision of civic education subjects can be used as a character building for the Indonesian nation for elementary school children.
\end{abstract}

Keywords: Citizenship Education, Character Development, National Character

Copyright (c) 2021 Dinie Anggraeni Dewi, Solihin Ichas Hamid, Maharani Sartika Dewi, Patricia Bunga Juwita Galand, Wenny Yolandha

$\triangle$ Corresponding author :

Email : maharanisartika@upi.edu

DOI : https://doi.org/10.31004/basicedu.v5i6.1634 
5242 Membina Karakter Bangsa Indonesia untuk Anak Sekolah Dasar melalui Pendidikan Kewarganegaraan - Dinie Anggraeni Dewi, Solihin Ichas Hamid, Maharani Sartika Dewi, Patricia Bunga Juwita Galand, Wenny Yolandha

DOI: https://doi.org/10.31004/basicedu.v5i6.1634

\section{PENDAHULUAN}

Perjalanan panjang bangsa Indonesia dalam menciptakan sistem berkeadilan sosial terus diwariskan dalam nilai-nilai luhur bangsa. Sistem berkeadilan memiliki cakupan yang luas seperti keadilan dalam memperoleh akses pendidikan yang layak dan fasilitas yang mempuni. Problematisasi pendidikan selalu dihadapkan pada pemenuhan akses, sistem pendidikan dan kurangnya antusiasme masyarakat untuk bersekolah (Collins, 2011). Salah satu faktor yang mendasari hal tersebut ialah permasalahan ekonomi, biaya sekolah yang mahal dan atribut pendidikan yang harus dibeli membuat sebagian masyarakat yang berpenghasilan rendah memilih bekerja daripada sekolah. Jaminan pendidikan untuk warga negara belum sepenuhnya terealisasi dengan baik, faktanya banyak ditemukan bahwa sebagian masyarakat berpenghasilan rendah memilih bekerja untuk memenuhi kebutuhan sehari-hari. Hal ini merupakan pekerjaan rumah bagi negara untuk mengentaskan kemiskinan salah satunya melalui pendidikan.

Pada dasarnya, pendidikan di Indonesia menjadi milik dan hak setiap warga negara tanpa tekecuali. Hak warga negara Indonesia merupakan sesuatu yang harus diperoleh setelah melaksanakan kewajiban sebagai warga negara. Hak mendapatkan pengajaran dan pendidikan telah tercantum dalam Pasal 31 ayat 1 dan 2 UUD 1945 bahwa "tiap-tiap warga negara berhak mendapatkan pendidikan". Oleh karenanya, "Pemerintah mengusahakan dan menyelenggarakan satu sistem pengajaran Nasional, yang diatur dengan undang-undang" (Kariadi, 2017).

Selain itu, menurut UUD 1945 yang memuat cita-cita bangsa menyebutkan bahwa pendidikan ialah hak segala bangsa. Memajukan pendidikan telah lama diperjuangkan oleh pejuang kemerdekaan Indonesia. Jika kembali pada historisitas zaman penjajahan, pendidikan hanya bisa diakses oleh kaum bangsawan dan keluarga yang memiliki privillege (Collins, 2011). Banyak bangsa Indonesia yang berjuang demi mendapatkan akses pendidikan, meskipun harus belajar secara diam-diam. Usaha ini tidak terhenti, pendidikan mulai menjadi prioritas yang diperjuangkan oleh bangsa Indonesia. Beberapa tokoh telah memberi sumbangsih dalam memajukan pendidikan Indonesia ialah Soetomo lewat berdirinya Budi Utomo. Berdirinya Budi Utomo menjadi awal bagi tumbuhnya semangat belajar bangsa Indonesia. Yang tidak kalah penting ialah perjuangan Ki Hajar Dewantoro dalam memberikan pengajaran yang setara tanpa diskriminasi, serta menanamkan nilai-nilai budi pekerti untuk membentuk karakter bangsa (Astriani, 2018). Dasar dari kemajuan bangsa berasal dari gagasan fundamental yang memberikan kesempatan bagi siapa saja untuk memperoleh pendidikan tanpa memandang latar belakang, suku, agama, ras dan kebudayaannya (Collins, 2011).

Suatu negara bisa maju dan bermartabat apabila memiliki sumber daya manusia yang berpendidikan dan memiliki karakter. Penanaman karakter bangsa bisa di tanamkan melalui pengamalan nilai-nilai luhur maupun melalui pendidikan. Secara tidak langsung, pendidikan bisa disebut sebagai kunci untuk menuju masa depan bangsa yang lebih baik. Salah satu upaya yang dilakukan pemerintah dalam membentuk karakter bangsaialah melalui pembelajaran pendidikan kewarganegaraan. Pendidikan kewarganegaraan telah ada sejak lama dan menjadi mata pelajaran wajib untuk bangsa agar memahami nilai-nilai luhur bangsa. Akan tetapi dalam perkembangannya, pendidikan kewarganegaraan masuk dalam pembelajaran yang kurang diminati khususnya generasi muda sekarang.

Keterkaitan Pendidikan Kewarganegaraan terhadap pengembangan karakter dikemukakan oleh Cogan (1998:13) yang menyatakan Pendidikan Kewarganegaraan adalah kontribusi atau dampak pendidikan terhadap pengembangan karakteristik yang menandai seorang warga negara. Maka dari itu, untuk mencapai warga negara yang berkarakter diperlukanlah lingkup pendidikan formal. 
5243 Membina Karakter Bangsa Indonesia untuk Anak Sekolah Dasar melalui Pendidikan Kewarganegaraan - Dinie Anggraeni Dewi, Solihin Ichas Hamid, Maharani Sartika Dewi, Patricia Bunga Juwita Galand, Wenny Yolandha

DOI: https://doi.org/10.31004/basicedu.v5i6.1634

Dipihak lain kontribusi yang sama juga disampaikan oleh Djahiri (2002:90) dalam pernyataannya adalah bahwa dalam pembinaan karakteristik warga negara tersebut diperlukan rekayasa pendidikan dengan mengacu pada falsafah negara dan menjadikan sekolah sebagai laboratorium kewarganegaraan yang demokratis.

Pendidikan kewarganegaraan selalu dibahas saat pergantian kurikulum agar kedepannya pendidikan ini masih terus dipertahankan. Berdasarkan Kurikulum Tingkat Satuan Pendidikan (KTSP), mata pelajaran pendidikan kewarganegaraan diajarkan mulai dari Sekolah Dasar. Selanjutnya, mata pelajaran ini dianggap berdiri sendiri dan tidak tergabung dalam rumpun ilmu sosial (IPS). Perombakan kurikulum yang menyangkut pendidikan kewarganegaraan salah satunya bertujuan untuk menghindari sistem pemerintah yang otoriter. Sebab, pendidikan kewarganegaraan merupakan pembelajaran dasar yang membentuk karakter dan moralitas suatu bangsa Indonesia. Karakter bangsa inilah yang selanjutnya menjadi tonggak bagi kemajuan bangsa dan negaranya.

\section{METODE PENELITIAN}

Dalam penulisan artikel ilmiah ini, digunakan penulisan deskriptif kualitatif. Yang memberikan gambaran menyeluruh mengenai suatu masalah yang berkembang dengan suatu gagasan kreatif yang akan dijadikan sebagai solusi yang inovatif.

Data data yang diperlukan dalam penulisan artikel ilmiah ini adalah hal hal yang berkaitan dengan sebuah pemikiran yang berhubungan tentang pendidikan karakter yang dilaksanakan didalam mata pelajaran pendidikan kewarganegaraan pada peserta didik Sekolah Dasar. Dalam penulisan artikel ilmiah ini digunakan dengan pedoman karya tulis ilmiah dari Universitas Pendidikan Indonesia tahun 2021 dan menggunakan metode pengumpulan data dengan membaca dan menelaah (metode literatur) yang berhubungan dengan permasalahan yang dikemukakan.

Analisis data dalam penulisan artikel ilmiah ini adalah dengan metode deskriptif kualitatif, yang membuat gambaran secara sistematis mengenai suatu permasalahan tertentu dengan solusi yang dapat diberikan. Kemudian hasilnya ditulis dalam bentuk analisis data kualitatif.

\section{HASIL DAN PEMBAHASAN}

Menurut UU Sistem Pendidikan Nasional No. 20 tahun 2003 menyatakan bahwa pendidikan merupakan usaha sadar dan terencana untuk mewujudkan suasana belajar dan proses pembelajaran yang secara aktif mengembangkan potensi diri agar memiliki kekuatan keagamaan, pengendalian diri, kepribadian, kecerdasan, akhlak mulia, serta keterampilan yang harus dimiliki oleh dirinya, masyarakat, bangsa dan negara (Budiutomo, 2013). Tidak hanya itu, pendidikan ialah kebutuhan dasar yang wajib dimiliki oleh setiap warga negara.

Negara-negara di dunia menempatkan pendidikan sebagai faktor penentu memajukan kesejahteraan dan kemajuan negara. Kualitas pendidikan yang baik diyakini bisa membawa perubahan dan kemajuan bagi suatu negara (Collins, 2011). Maka dari itu, setiap negara akan berusaha menciptakan sistem pendidikan yang baik bagi rakyatnya. Masing-masing negara telah merancang sistem pendidikan yang disesuaikan dengan nilai kebudayaan dan sumbe daya manusianya (rakyatnya). Melalui hal ini, sistem pendidikan bisa mengarah pada pembentukan kualitas daripada kuantitas. Dalam konteks makro, tujuan pendidikan yang ingin dicapai suatu negara adalah menciptakan konsensus dan menjadikan warga negaranya berpengetahuan luas, berkarakter, bertanggung jawab pada hidupnya dan negaranya (Anisah, 2018). Nilai-nilai tersebut juga menjadi tujuan bagi pendidikan yang sedang dirintis Indonesia. 
5244 Membina Karakter Bangsa Indonesia untuk Anak Sekolah Dasar melalui Pendidikan Kewarganegaraan - Dinie Anggraeni Dewi, Solihin Ichas Hamid, Maharani Sartika Dewi, Patricia Bunga Juwita Galand, Wenny Yolandha

DOI: https://doi.org/10.31004/basicedu.v5i6.1634

\section{Dampak Globalisasi terhadap Pendidikan}

Pendidikan merupakan tindakan fundamental yang terimplementasikan melalui perbuatan yang menyentuh akar kehidupan dan menciptakan jiwa kemanusiaan. Perkembangan teknologi dan informasi dalam era globalisasi adalah tantangan negara untuk menciptakan pendidikan yang humanis tanpa meninggalkan nilainilai luhur bangsa. Dampak perkembangan zaman tidak bisa pungkiri bisa mengancam penerapan nilai-nilai luhur bangsa dalam sistem pendidikan Indonesia. Kemajuan tekonologi dan informasi berlangsung secara cepat dan transparan sehingga bisa diakses siapa saja, tidak memandang umur dan kelas sosial (Budiutomo, 2013). Muncul kekhawatiran di masyarakat bahwa kemajuan teknologi yang tidak diimbangi oleh sumber daya manusia yang mempuni akan menimbulkan dampak negatif.

Keresahan masyarakat beralasan setelah munculnya tindakan amoral dan anarkisme yang meresahkan lingkungan masyarakat. Pelaku tindakan tersebut ialah generasi muda, hal ini membuat miris sekelompok masyarakat. Bahwasanya generasi muda merupakan penerus bangsa. Problematisasi ini bisa dikatakan sebagai kegagalan sistem pendidikan. Perkembangan zaman yang semakin pesat belum sepenuhnya diantisipasi oleh sistem pendidikan Indonesia. Sistem pendidikan yang dibuat Pemerintah belum siap menerima perubahan dan kemajuan tekonologi, terlebih Indonesia masih tertinggal dalam memajukan sumber daya manusianya. Menciptakan generasi penerus bangsa di era globalisasi dan krisis multi dimensional membutuhkan kerja keras dari semua pihak baik lembaga pemerintahan, pendidikan dan keluarga. Pendidikan Indonesia harus memfokuskan pada implementasi nilai-nilai luhur bangsa sesuai Pancasila.

Tantangan globalisasi menjadi tugas bersama baik lembaga pemerintahan, pendidikan, masyarakat maupun keluarga. Hal utama yang wajib dipertahankan ialah nilai kebudayaan dan solidaritas bangsa Indonesia untuk melawan dampak negatif dari globalisasi. Untuk mempertahankan nilai budaya, solidaritas dan karakter bangsa dibutuhkan pendidikan kewarganegaraan. Pendidikan ini harus dirancang, diajarkan dan diimplementasikan dalam kehidupan bernegara. Pendidikan kewarganegaraan harus dilaksanakan secara elaboratif agar generasi muda bisa dengan mudah menyerap nilai-nilai yang diajarkan. Selain itu, pendidikan kewarganegaraan harus diajarkan kepada generasi muda sedini mungkin.

\section{Peran Pendidikan Kewarganegaraan}

Pendidikan kewarganegaraan telah banyak dibahas, pendidikan ini mengkaji aspek-aspek kenegaraan seperti rule of law (peraturan hukum), proses demokrasi, konstitusi dan hak asasi manusia. Aspek penting yang diangkat dalam pendidikan kewarganegaraan ialah menciptakan warga negara menjadi manusia yang baik dan bermartabat (Yusra, 2006). Pendidikan kewarganegaraan merupakan disiplin ilmu yang wajib diikuti secara sadar dan aktif agar nilai-nilai di dalamnya bisa diimplementasikan dalam kehidupan (Sudirman, 2021). Pemerintah Indonesia sedang mempersiapkan generasi muda untuk mampu bersaing dengan bangsabangsa lain dalam memajukan negaranya. Pencapaian kualitas sumber daya manusia diupayakan melalui pemerataan pendidikan di semua wilayah Indonesia.

Pendidikan kewarganegaraan didasarkan pada perjuangan bangsa yang telah melahirkan kekuatan yang luar biasa baik secara fisik maupun non fisik. Perjuangan ini dilandasi wawasan dan kesadaran bangsa sebagai bukti kecintaan pada tanah air yang berpegang teguh pada nilai-nilai Pancasila (Monteiro, 2015). Kunci dari pendidikan kewarganegaraan ialah untuk membantu olah pikir, hati dan karsa pada generasi muda (Astriani, 2018).

Mekanisme pengajaran pendidikan kewarganegaraan disesuaikan dengan kurikulum yang telebih dulu di atur oleh Kementrian Pendidikan dan Kebudayaan RI. Mekanisme pengajaran pendidikan kewarganegaraan dimulai dan diiniasi oleh lembaga pendidikan. Terutama lembaga pendidikan ditingkat dasar yakni SD (Sekolah 
5245 Membina Karakter Bangsa Indonesia untuk Anak Sekolah Dasar melalui Pendidikan Kewarganegaraan - Dinie Anggraeni Dewi, Solihin Ichas Hamid, Maharani Sartika Dewi, Patricia Bunga Juwita Galand, Wenny Yolandha

DOI: https://doi.org/10.31004/basicedu.v5i6.1634

Dasar). Sekolah adalah tempat untuk membentuk "makhluk baru" yakni anak-anak untuk di didik dan diarahkan untuk menemukan bakat dan jati dirinya. Selain itu, lembaga sekolah berperan penting dalam menanamkan nilai-nilai moral kepada anak-anak agar menjadi pribadi yang berkarakter (Ritzer, 2011)r. Maksud berkarakter disini ialah anak-anak sudah dibekali nilai dan prinsip moral untuk dijadikan pegangan dalam menjalani kehidupan bermasyarakat.

Dalam mengajar pendidikan kewarganegaraan tentu membutuhkan interaksi antara guru dan murid. Interaksi ini dimaksudkan untuk membangun suasana belajar mengajar yang menyenangkan tanpa menimbulkan paksakan. Baik guru maupun murid harus memiliki konsensus yang baik dalam mengimplementasikan nilai-nilai yang diajarkan melalui pendidikan kewarganegaraan (Yusra, 2006). Implementasi pembelajarannya, guru harus bisa mengintegrasikan nilai-nilai dalam mata pelajaran menggunakan bahasa yang mudah di mengerti oleh murid. Selanjutnya, guru harus memberikan contoh sederhana dari penanaman nilai tersebut. Seperti halnya, mengajarkan anak untuk saling tolong menolong, menghormati orang yang lebih tua, dan menanamkan nilai toleransi sejak dini. Nilai yang diimplementasikan melalui tindakan langsung akan mudah dimengerti anak-anak, sehingga ada kecenderungan bagi mereka untuk mengingat dan menirunya (Collins, 2011).

Lembaga sekolah merupakan sarana utama untuk memberikan pengajaran pendidikan kewarganegaraan bagi anak-anak. Komitmen ini harus disepakati lembaga sekolah agar anak-anak mendapatkan wawasan kebangsaan dan nilai-nilai luhur bangsa. Selain itu, pendidikan kewarganegaraan harus menjadi basis untuk penguatan moralitas anak-anak. Pasalnya, seiring berkembangnya zaman, moralitas menjadi nilai yang kabur dan tergerus oleh arus globalisasi sehingga peran pendidikan kewarganegaraan sangat dibutuhkan untuk menghalau dampak negatif dari arus globalisasi.

Pada dasarnya, pemahaman yang diperoleh anak-anak berangkat dari sistem kepercayaan yang diyakini, citra diri serta kebiasaan yang melingkupinya. Pendidikan kewarganegaraan mempengaruhi pola pikir dan cara mengatasi permasahalan di kehidupan sehari-hari, sehingga mengantarkan anak untuk berani mengambil dan bertanggung jawab atas keputusan yang diambil (Monteiro, 2015). Selain itu, pendidikan kewarganegaraan memiliki peran dalam mentransfer nilai kebudayaan dan perdamaian dimana nilai tersebut harus direkulturasi dalam pembelajaran kewarganegaraan. Rekulturasi nilai-nilai yang hendak dicapai dalam pendidikan kewarganegaraan ialah nilai perdamaian, hak asasi manusia dan pembangunan berkelanjutan.

Pendidikan kewarganegaraan pada anak sekolah dasar diharapkan mampu menjadi fondasi bagi yang menumbuhkan semangat kebhinekaan dan bangga menjadi warga negara Indonesia. Peran pendidikan kewarganegaraan sangat luas tidak hanya mengamalkan nilai Pancasila tetapi juga tentang demokrasi, bela negara, nasionalisme dan membentuk karakter penerus bangsa Indonesia (Kariadi, 2017). Lembaga sekolah menjadi basis dan leading sectors yang harus menjaga komitmen untuk menjadi fasilitator, pemecah masalah dan mencotohkan komitmen untuk menciptakan generasi yang memegang nilai-nilai luhur bangsa (Anisah, 2018). Peran pendidikan kewarganegaraan diharapkan tidak hanya berhenti pada pembentukan karakter bangsa namun juga menjadikan anak-anak sebagai agent of change di lingkungannya. Peranan ini dimaksudkan untuk menciptakan pola pikir anak-anak agar mampu menjadi individu yang berguna bagi dirinya sendiri dan masyarakat.

\section{Pembangunan Karakter Bangsa melalui Pendidikan Kewarganegaraan}

Membentuk dan membangun karakter seseorang menjadi lebih baik bukanlah hal yang mudah. Sebab, setiap orang memiliki latar belakang yang berbeda-beda. Karakter seseorang bisa tebentuk melalui faktor internal maupun eksternal. Faktor internal adalah faktor yang muncul dalam diri seseorang, berasal dari pikiran dan watak yang menjadi ciri khas sejak lahir. Selanjutnya, faktor eksternal pembentuk karakter seseorang datang dari lingkungan dan melalui pengajaran. Faktor eksternal nantinya menjadi penentu pembangunan karakter 
5246 Membina Karakter Bangsa Indonesia untuk Anak Sekolah Dasar melalui Pendidikan Kewarganegaraan - Dinie Anggraeni Dewi, Solihin Ichas Hamid, Maharani Sartika Dewi, Patricia Bunga Juwita Galand, Wenny Yolandha

DOI: https://doi.org/10.31004/basicedu.v5i6.1634

seseorang. Karakter ini muncul karena pengajaran (melalui sekolah), latihan dan kebiasaan-kebiasaan yang dicontohkan orang tua maupun guru. Pembentukan karakter tersebut tidak terlepas dari penanaman nilai yang telah diperoleh seseorang ketika menempuh pendidikan di sekolah dasar.

Sasaran pengembangan karakter bangsa ialah sumber daya manusia yang masih membutuhkan dorongan dan pembelajaran mengenai nilai-nilai luhur bangsa. Setiap warga negara berkewajiban mengamalkan nilai-nilai luhur bangsa baik dalam kehidupan bernegara maupun bermasyarakat (Anisah, 2018). Konteks yang lebih luas, upaya membangun sumber daya manusia yang berkarakter tidak terlepas dari tantangan global yangsaat ini tengah di hadapi Indonesia. Jika anak-anak sekolah dasar bisa mengimplementasikan nilai yang ada dalam pendidikan kewarganegaraan melalui tindakan sederhana, sudah barang tentu sebagai generasi muda jugaharus memiliki sikap dan keberanian dalam menghadapi tantangan global.

Dalam pendidikan kewarganegaraan, tantangan global juga menjadi aspek yang bisa melunturkan nilainilai kebudayan bangsa sendiri. Oleh karenanya, untuk menghadapi hal tersebut Indonesia membutuhkan generasi penerus bangsa yang memiliki karakter kuat. Agar stigma mengenai kurangnya kepedulian terhadap negara mulai luntur digantikan dengan komitmen menjadi warga negara yang berkarakter. Lebih lanjut, nilai dalam pendidikan kewarganegaraan tidak hanya berisi wawasan nusantara dan nilai budi pekerti, namun juga mengandung nilai profesionalitas, tanggung jawab, dan nilai kesadaran bernegara. Dimana nilai-nilai tersebut turut membentuk karakter seseorang menjadi lebih baik.

Secara tidak langsung, gencarnya upaya pemerintah untuk membangun karakter bangsa membuat tolak ukur masyarakat menjadi berbeda dalam melihat seseorang. Kurang lebihnya, masyarakat memandang tindakan bermasyarakat didasarkan pada karakter yang ada di dalam diri seseorang. Karakter yang baik sudah tentu tercermin dari moralitas yang ia tampilkan yakni ukuran baik burknya seseorang tersebut (Anisah, 2018). Karakter seseorang dititik beratkan pada indikator seberapa bermoralkah dia dan seberapa baikkah dia menjadiwarga negara Indonesia. Moralitas menyangkut nilai normati tentang baik buruknya seseorang, nilai ini bisa dibentuk berdasarkan ketentuan-ketentuan tertentu (Ritzer, 2011).

Terdapat hal yang tidak disadari masyarakat bahwa menciptakan warga negara yang baik adalah upaya pemerintah dalam membentuk suatu konsensus yang saling berintegrasi. Dengan latar belakang kebudayaan, agama, suku bangsa yang berbeda-beda upaya menyatukan ialah melalui pendidikan kewarganegaraan. Nilainilai luhur bangsa yang membangun karakter seseorang bisa menjadikan seseorang menjadi warga negara yang baik (good citizen). Yang termasuk dalam warga negara yang baik ialah mereka yang menjunjung tinggi nilainilai luhur bangsa Indonesia, terutama pengamalan sila-sila di Pancasila sebagai dasar negara.

\section{KESIMPULAN}

Sekolah dasar diakui memiliki peran penting dalam pengembangan fondasi karakter individu. Pendidikan karakter sangat penting diterapkan di sekolah dasar, apalagi pada saat sekarang perkembangan teknologi globalisi semakin pesat yang nantinya seluruh elemen masyarakat baik masih kecil maupun sudah besar mampu menerima dengan baik. Pembinaan karakter pada siswa yang dapat dilakukan salah satunya dengan pemberian mata pelajaran pendidikan kewarganegaraan. Pendidikan kewarganegaraan merupakan pendidikan yang penting untuk terus dilestarikan dan ditetapkan menjadi pendidikan utama untuk membentuk karakter bangsa. Salah satu nilai yang terkandung dalam pengajaran pendidikan kewarganegaraan adalah toleransi dan nilai moralitas. Perbedaan suku, negara, ras dan daerah dapat menumbuhkan nilai toleransi antar masyarakat yang harus dibangun sejak dini. Pendidikan kewarganegaraan juga akan membentuk karakter yang berasazkan nilai-nilai Pancasila salah satunya untuk menghindari disintegritas yang membuat bangsa menjadi terpecah belah. Proses pembentukan karakter yang dilakukan sejak dini di sekolah akan memberikan dampak yang besar bagi kehidupan bermasyarakat, berbangsa, dan bernegara. 
5247 Membina Karakter Bangsa Indonesia untuk Anak Sekolah Dasar melalui Pendidikan Kewarganegaraan - Dinie Anggraeni Dewi, Solihin Ichas Hamid, Maharani Sartika Dewi, Patricia Bunga Juwita Galand, Wenny Yolandha

DOI: https://doi.org/10.31004/basicedu.v5i6.1634

\section{DAFTAR PUSTAKA}

Abidin, R. Fajar. (2015). Peran Guru Pendidikan Kewarganegaraan Dalam Mengembangkan Kecerdasan Moral Siswa. Jurnal Kultur Demokrasi, 3(1).

Agus, A. A. (2015). Pendekatan Pendidikan Kewarganegaraan Sebagai Pendidikan Nilai Moral Di Sekolah Dasar. Jurnal Pemikiran, Penenlitian Ilmu-Ilmu Sosial, Hukum, Dan Pengajarannya, 10(1), 36-41.

Anastasya, E. (2021). Mata Pelajaran Pendidikan Kewarganegaraan Sebagai Pendidikan Karakter Peserta Didik Sekolah Dasar. Jurnal Pendidikan Kewarganegaraan Undiksha Vol. 9 No. 2

Andrian. (2017). Pengembangan Karakter Siswa Melalui Pendidikan Kewarganegaraan. Untirta Civic Education Journal. Vol. 2 No. 1 Hal 17-30.

Anisah, S. (2018). Optimalisasi Peran Keluarga Dan Sekolah Sebagai Basis Penguatan Apiru Dan Pustaka Pelajar.

Astriani, C. (2018). Pemikiran Ki Hajar Dewantoro Dalam Mewujudkan Sekolah Inklusif Sebagai Bangsa. Konstruksi Sosial. Jurnal Penelitian Ilmu Sosial, Vol. 1(No. 6).

Atika, N. T., Wakhuyudin, H., \& Fajriyah, K. (2019). Pelaksanaan Penguatan Pendidikan Karakter Membentuk Karakter Cinta Tanah Air. Mimbar Ilmu, 24(1), 105-113.

Budiutomo. (2013). Pendidikan Kewarganegaraan Dalam Membentuk Karakter Bangsa. Academy.

Cahyo, E. D. (2017). Pendidikan Karakter Guna Menanggulangi Dekadensi Moral Yang Terjadi Pada Siswa Sekolah Dasar. Eduhumaniora| Jurnal Pendidikan Dasar Kampus Cibiru, 9(1), 16-26.

Cogan, J.J. (1998). Citizenship For The 21 Century : An International Perspective On Education. London : Cogan Page

Collins, D. (2011). Paulo Friere: Kehidupan, Karya Dan Pemikiran. Yogyakarta: Komunitas Indonesia Melalui Demokrasi, Ham Dan Masyarakat Madani. Jurnal Pendidikan Ilmu Sosial.

Djahiri, A.K. (2006). Pendidikan Nilai Dan Moral Dalam Dimensi Pkn. Bandung : Lab. Pkn Upi.

Fauzi, Fadil Yudia, Ismail Arianto Dan Etin Solihatin. 2013. Peran Guru Pendidikan Pancasila Dan Kewarganegaraan Dalam Upaya Pembentukan Karakter Peserta Didik. Jurnal Ppkn Unj Online: Volume 1, Nomor 2, Hal. 1-15

Galuh, D.A., Dkk. (2021). Urgensi Nilai Dan Moral Dalam Upaya Meningkatkan Pendidikan Karakter Melalui Pembelajaran Pkn Di Sekolah Dasar. Jurnal Basicedu Vol. 5 No. 6.

Juliardi, B. (2015). Implementasi Pendidikan Karakter Melalui Pendidikan Kewarganegaraan. Jurnal Bhinneka Tunggal Ika. Jurnal Civic Hukum, 2(2), 3. Https://Doi.Org/10.22219/Jch.V1i1.10457

Kariadi, D. (2017). Menciptakan Generasi Yang Berwawasan Global Berkarakter Lokal Melaui Harmonisasi Nilai Kosmopolitan Dan Nasionalisme Dalam Pembelajaran. Graha Ilmu.

Kesuma, I. T. V. Y. (2019). Peran Pendidikan Kewarganegaraan Dalam Membangun Karakter Bangsa. Wahana Didaktika: Jurnal Ilmu Kependidikan 17, 1, 84-92.

Lestari, A. (2021). Analisis Program Pelaksanaan Penguatan Pendidikan Karakter (Ppk) Di Sekolah Dasar. Jurnal Basicedu, Vol 5 No. 3.

Monteiro, J. (2015). Pendidikan Kewarganegaraan : Perjuangan Membentuk Karakter Bangsa.

Pancasila, A. P. P. (N.D.). Pendidikan Karakter. Jurnal Ppk, Vol. 6, No.

Ritzer, G. (2011). Teori Sosiologi.Yogyakarta: Kreasi Kencana Singkawang. Jurnal Pancasila Dan Kewarganegaraan, Vol.1, No.2. 
5248 Membina Karakter Bangsa Indonesia untuk Anak Sekolah Dasar melalui Pendidikan Kewarganegaraan - Dinie Anggraeni Dewi, Solihin Ichas Hamid, Maharani Sartika Dewi, Patricia Bunga Juwita Galand, Wenny Yolandha

DOI: https://doi.org/10.31004/basicedu.v5i6.1634

Sudirman, P. ; D. (2021). Pendidikan Kewarganegaraan Dalam Upaya Membangun Karakter. Drepublish.

Yusra, D. (2006). Membangun Karakter Dan Kepribadian Melalui Pendidikan. 